\title{
Cycle time reduction in Deck roller assembly production unit with Value Stream Mapping analysis
}

\author{
Chaitanya Gangal $^{\text {a }}$, Mishank Modi ${ }^{a}$, V. K. Manupati ${ }^{\text {a }}$, M. L. R. Varela ${ }^{\text {b }}$ J. Machado ${ }^{c}$, J. \\ Trojanowska $^{\mathrm{d}}$ \\ ${ }^{a}$ Department of Manufacturing, School Of Mechanical and Engineering Sciences, VIT \\ University, Vellore-632014, Tamil Nadu, India. \\ ${ }^{b}$ Department of Production and Systems, School of Engineering, University of Minho, \\ Guimaraes, Portugal. \\ ${ }^{c}$ Department of Mechanical Engineering, School of Engineering, University of Minho, \\ Guimaraes, Portugal. \\ ${ }^{d}$ Department of Management and Production Engineering, Poznan University of Technology, \\ Poznan, Poland
}

E-mail: gangal.chaitanya@gmail.com,mishank.modi2015@vit.ac.in, manupativijay@gmail.com, leonilde@dps.uminho.pt,jmachado@dem.uminho.pt, justyna.trojanowska@put.poznan.pl

\begin{abstract}
Cycle time reduction is of paramount importance in a manufacturing industry as the customer not only emphasizes on the quality of the product but also takes into consideration the timely delivery of the product. The proposed framework and the advanced methodology in this paper are capable of dealing with each stage of the considered manufacturing unit by maximizing the value of the product through reduction of cycle times and minimization of waste. The time required for all the processes in the manufacturing of the deck rollers is identified and are classified into value added (VA) and non-value added (NVA). Finally, the cycle times were reduced by applying the lean tools and principles on some managerial relevances. Also, Arena software was used to simulate the current and future value stream maps and the change in the cycle times, waiting times, machine utilization, etc. was determined.
\end{abstract}

Keywords: Lean thinking concepts, value stream mapping, cycle time, Arena simulation software.

\section{Introduction}

Cycle time reduction plays a vital role when an organization is aiming to increase its efficiency, productivity and customer responsiveness. Cycle time is the time taken to do any particular task from the starting point of one process on a particular machine until the end of the last process in the sequence for the production of a part. This cycle time can be measured using 
time study techniques such as StopWatch time study, and Maynard Operation Sequence Technique (MOST) (Fang, 2015). During the time study, a process can be divided into a number of work elements and are classified into value added (VA) activities which augment the value of the product such as machining, assembling, painting, etc. and non-value added (NVA) activities which have no effect on the value of the product such as loading, unloading, cleaning the machine, material handling, dimension checking, unwanted tool and operator movement.

Lean Manufacturing manages to eliminate waste, improve throughput, reduce inventory and encourage workers to bring attention to problems and suggest solutions to fix them. It was developed by Toyota Production system and can be established as a formal approach to manufacturing that aims to reduce the cycle time of processes, improve quality and increase the flexibility. The fundamental objective of Lean Manufacturing is to maximize customer value while minimizing the waste and thus achieving the manufacturing fineness by producing more value with the minimum resource. Tools which are used to incorporate Lean Manufacturing in flow production design includes Value Stream Mapping (VSM), Cellular Manufacturing (CM), Single Minute Exchange of Dies (SMED) and Continuous Improvement (CI)/Kaizen.

In product development phase VSM plays a vital role in designing a flawless production procedure. The procedure includes eliminating the various interruptions such as factoryspecific restriction while considering the manufacturing objectives such as product quality, the time required for the product to reach customer and equipment capability. In a next stage, VSM has to take care of the customer satisfaction for which the new technologies can be used in the manufacturing.

In this research work, we have developed a framework of the proposed methodology for improving the efficiency and the effectiveness of the considered case study. A case demonstrated in this paper is based on the manufacturing unit with production and assembly of deck rollers located in India. The detailed case description is demonstrated in section 3, and its processes are depicted in Figure (2) In order to achieve the objective, i.e., cycle time reduction, the research study starts with implementing the VSM analysis and a performance check of the current production process design. It includes Gemba walk for scan and plan process object by real field visit and calculation of Takt time and cycle time to draw Paretodiagram. Pareto diagram gives the current view of the process i.e. the state of each process. These different stages can then be used to draw the current value stream map. Value stream 
design starts with a cycle time reduction of the process in which real optimization is possible. After the cycle time reduction, we draw the future value stream map based on the new values calculated. Thus the paper provides a validation of the used methodology by giving the production process design with a significant decrease in cycle time with higher transparency in production control.

The paper has been organized as follows: The detailed literature review is presented in Section 2. A brief summary of the considered product and the company background is given in Section 3. Section 4 provides the detailed methodology proposed to obtain the current and future value stream map by discussing the different scenarios and the novel ideas used for the improving the efficiency of the various production methods and also visualizes the improvements through future value stream maps. The ARENA based simulation and discussion about the results have been summarized and visualized in section 5. In section 6 the necessary conclusions are derived depending on the results from the current and future value stream map.

\section{Literature review}

Rahul et al. (2014) aimed to improve the efficiency of a multi-model assembly line by identification and elimination of non-value added activities, making changes in workstations, improvement of the layout to eliminate unwanted operator movements, and work content reduction using postural analysis of operators by implementing REBA (Rapid Entire Body Assessment) analysis. Gnanavel et al. (2015) demonstrated the implementation of a looping layout which was designed ergonomically in the assembly line of automobile ancillary unit labor demanded lean environment. The current process line and the proposed layout were simulated, and results were compared. The analysis showed a decrease in the total cycle time, increased balancing of workloads in the production line, increased alertness among workers and therefore increased productivity.

The lean thinking (LT) term was first coined by Womack et al. (1990) in his book "The Machine That Changed the World." It suggests that the fundamental concept of the waste minimization can be achieved by questioning the basic understanding of business and manufacturing. Sundar et al. (2014) studied the lean manufacturing tools such as Cellular Manufacturing (CM), Line Balancing, Value Stream Mapping (VSM), Inventory control, Uline system, Single Minute Exchange of Dies (SMED), Production Levelling, Pull System, Kanban, etc. Russell and Taylor (1999), mentioned many lean tools such as standard work 
Kaizen, one piece flow, VSM, poke yoke, and visual control to decrease the waste in manufacturing. Lean thinking concepts and tools have also been implemented that are proved to be a benefit in many other organisations like management (Ballard and Howell, 2003), healthcare (Bamford and Lodge,2007), supply chain management (Cudney and Elrod, 2010), environmental management ( Yang Mark et al. 2011 ), semi-process industry(Pool et al., 2011), energy management (Quinn, 2012), food industry (Simons and Taylor, 2007), public services (Radnor and Boaden, 2008), among others, in addition to manufacturing (Panizzolo, 1998; Seth and Gupta, 2005; Herron and Braiden, 2006; Worley and Doolen, 2006; Demeter and Matyusz, 2011).

Value stream mapping tool can be implemented effectively by forming a current state map for eliminating the non-value added activities, also to derive a future state map for reducing the cycle time and improve the process efficiency was proposed by Arvind et al. (2014). Stefan et al. (2014) investigated all the available analytical techniques for work measurement. The outcome was a rating of all the work measurement methods for the Cellular Manufacturing. The applicability of this approach was verified and was used as a reference for further examination of remaining lines. The cycle time analysis, together with the use of Arena software simulation was done based on the data collected by the time study. Thus, the paper aims to use the benefit value stream mapping (VSM) approach which is a lean principle to describe the expected results through its application. The authors present the proposed strategy in Figure (3). The VSM tool simplifies the process by eliminating the wasteful or the non-value adding activities from the process rather than just analyzing the process. The next section details the implementation of the various lean tools used for reducing the cycle times of operations and further creating a sustainable production system.

\section{Case study of ABC Company}

This study is focused on the manufacturing of Deck Roller assembly used in surface miners, apron feeders, materials handling, automotive, textile, etc. produced in $\mathrm{ABC}$ industry. $\mathrm{ABC}$ is a major technology, engineering, construction, manufacturing and financial services conglomerate, with global operations. It addresses critical needs in the major sectors Hydrocarbon, Infrastructure, Power, Process Industries, and defence - for customers in over 30 countries around the world. It is engaged in core sectors of the economy, and their integrated capabilities are focused on the concept of 'design to deliver.' With over seven decades of a strong, customer-focused approach and a continuous pursuit of world-class quality, they not 
only have expertise in many fields like Technology, Engineering, Construction, Infrastructure Projects and Manufacturing but also maintain leadership in all the key lines of business. The Company's manufacturing footprint extends across eight countries in addition to India. In the Figures (1) below, we have shown the deck roller assembly used in ABC Company and its detailed description is described as follows:

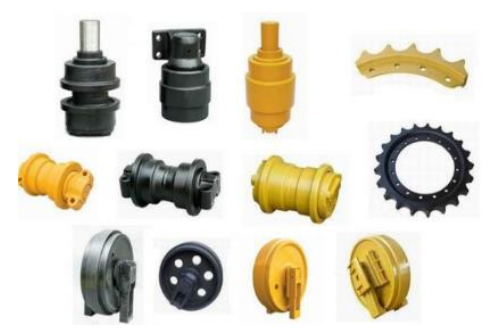

Figure 1. Roller Assembly.

The three variants available in deck roller assembly are T13, T23 and T50. There is a total of 14 operators required for the production of these components, and the average monthly demand is 250 deck rollers. This production line has been started recently, so it requires some standardization and optimization. Out of three variants available, the operations flow chart for the T23 deck roller assembly is shown in the flowchart as an example in Figure (2).

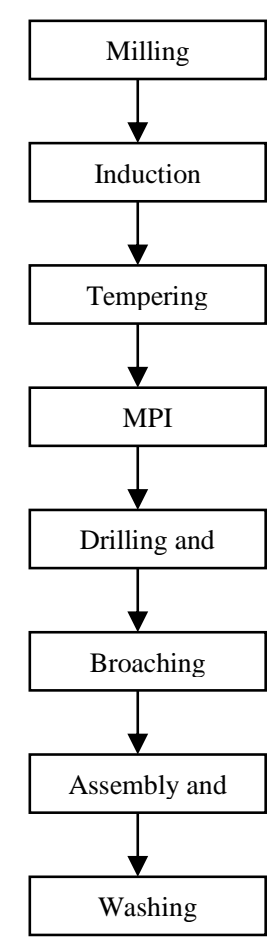

Figure 2. Flow diagram for T23 deck roller. 
The Figure (2) depicts that the deck roller undergoes milling, Induction Hardening, Tempering, Magnetic Particle Testing, Drilling and boring, Broaching, Oil Filling and Assembly. The time taken by each operator to do a specific process is different from each other. The workstation assigned to each operator varies according to the production schedule. The objective of this study is to calculate the cycle time of all the existing process using time study and work study techniques and then optimize them wherever possible using lean tools to reduce the overall cycle time of the process and to schedule the production accordingly

\section{Methodology}

The proposed methodology for reducing cycle time is considered in a case study for the system analysis and to improve its performance by eliminating the inefficient processes. Figure (3) shows the proposed methodology approach and its step by step process of applying different methods. These techniques include the 3G's (Gemba, Gembutsu, and Genjitsu), time study, work study and Kanban principle. Thereafter, VSM is used for drawing the current and future stream maps to compare the difference between the cycle times before and after their reduction.

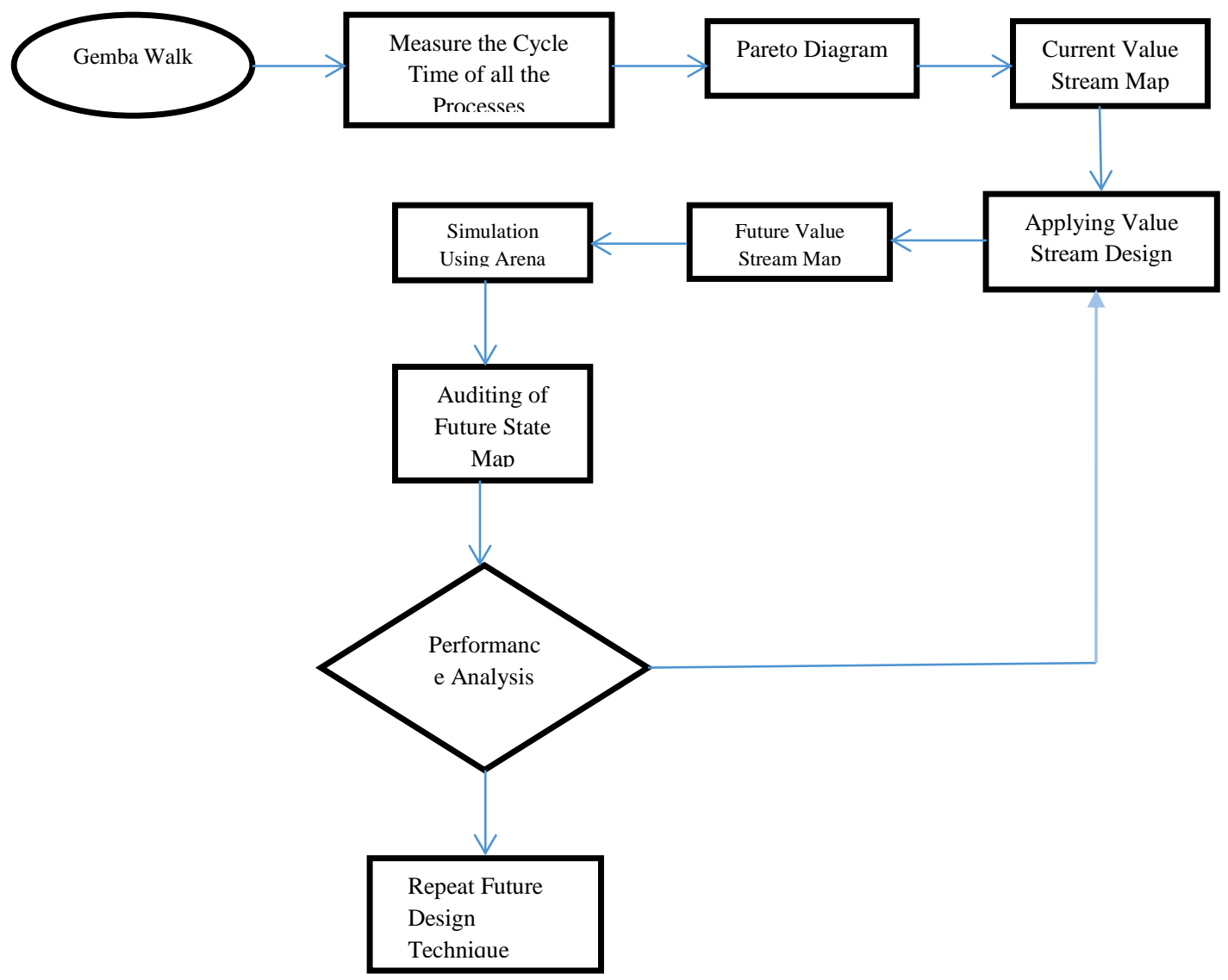

Fig 3. Flowchart of the proposed methodology. 


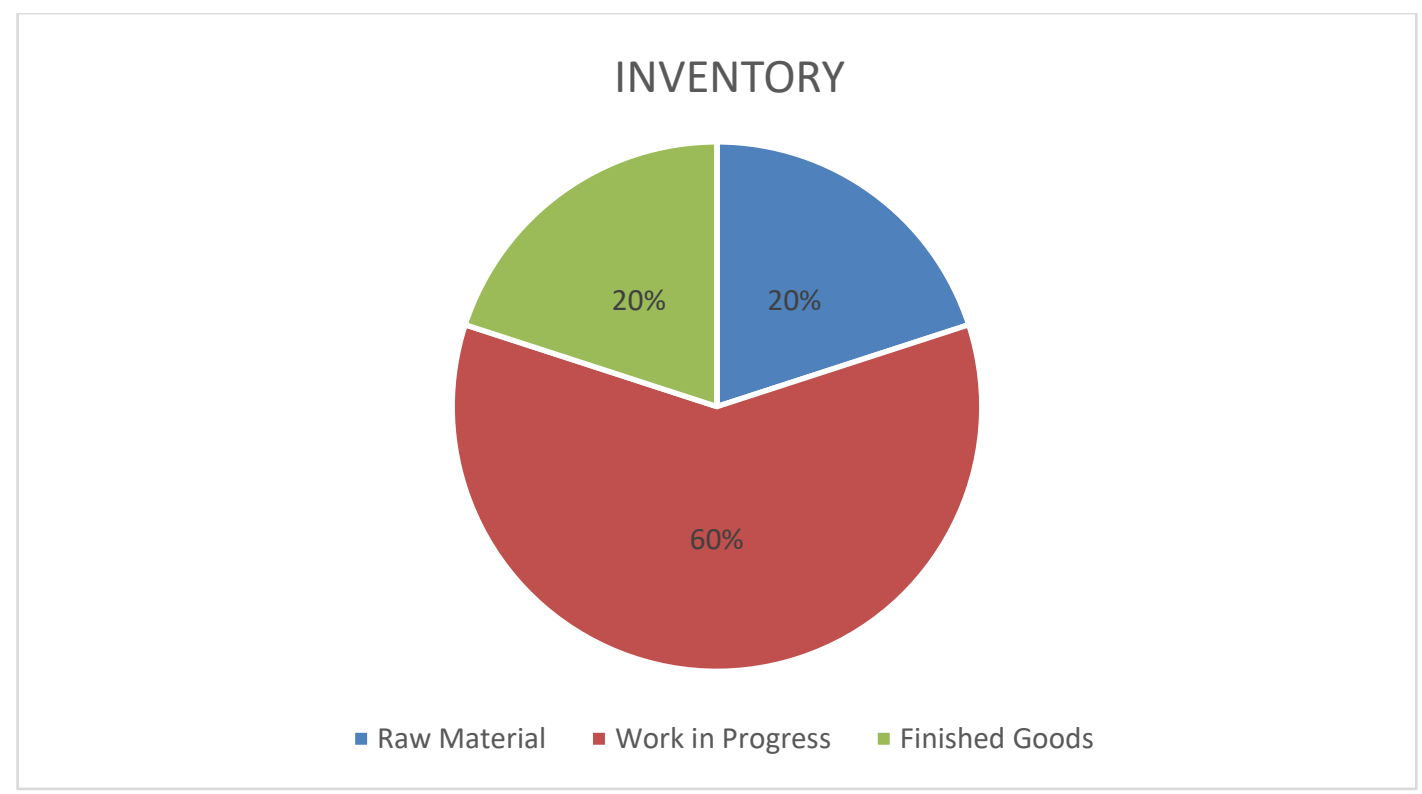

Figure 4. Types of inventory.

The details about the various types of inventories such as raw materials, work in progress and finished goods in the production line were obtained and are represented in Figure (4). It is evident from the pie chart that work in progress accounts for $60 \%$ of the total inventory, and thus it became the priority for being reduced. There was work in progress in almost every workstation of the production line. It was not possible to eliminate it immediately. So a step by step Kanban procedure was implemented to reduce the WIP over a period.The table (1) represents the amount of WIP inventory for each process in the manufacture of deck rollers. In the table (2) thus represents the inventory after Kanban principles were applied. We can see that the inventory for the alternative processes for the production of deck rollers is set to 0 . Also, the total WIP required has been reduced and thus waste is eliminated.

Table 1.Inventory before Kanban

\begin{tabular}{|l|l|}
\hline \multicolumn{2}{|c|}{ CASE 1 } \\
\hline Processes & $\begin{array}{l}\text { Inventory count at each } \\
\text { workstation (roller } \\
\text { section) in pairs }\end{array}$ \\
\hline Induction Hardening & 200 \\
\hline MPI & 200 \\
\hline
\end{tabular}




\begin{tabular}{|l|l|}
\hline Broaching & 150 \\
\hline Drilling and Tapping & 50 \\
\hline Turning & 250 \\
\hline Total WIP & 850 \\
\hline
\end{tabular}

Table 2.Inventory after Kanban

\begin{tabular}{|c|c|}
\hline \multicolumn{2}{|c|}{ CASE 1 } \\
\hline Processes & $\begin{array}{c}\text { Inventory count at each } \\
\text { workstation (roller } \\
\text { section) in pairs }\end{array}$ \\
\hline Induction Hardening & 0 \\
\hline MPI & 100 \\
\hline Broaching & 75 \\
\hline Drilling and Tapping & 100 \\
\hline Turning & 25 \\
\hline Total WIP & 300 \\
\hline
\end{tabular}

\subsection{Value Stream Mapping}

\subsubsection{Time Computation (Calculation of Takt Time)}

The word Takt in German means rhythm or pace. Takt time is the rate at which we need to produce our product to satisfy customer demand.

$$
T=\frac{T_{a}}{D}
$$

In equation (1) $\mathrm{T}$ represents Takt time, $\mathrm{T}_{\mathrm{a}}$ represents total available time and $\mathrm{D}$ accounts for the total demand. The Takt time is calculated for the roller. The demand for rollers is 250 per week and the available time calculated by the number of working days is 26 and number of minutes per day are 460 , then for 26 days the time is 10,920 minutes. Thus the Takt time for 
the rollers was obtained as 43.68 minutes. The calculations were carried out based on the total time available for the production of the parts and their total weekly demands. Thus the actual rate at which the production of the parts should be carried out was determined, and they act as ideal rates by which the actual production rates can be compared and improved. Cycle time represents the total time required for manufacturing a product. It takes into account the setup time, handling time, non-operation time and the actual operation time. Cycle time can be calculated for the deck roller production using the time study and work study techniques. Table 3 denotes the cycle times for different operations in the manufacture of the four variants in the return roller assembly. The process of time study has to be carried many number of times on different days and during different shifts to get the most appropriate cycle time.

Table 3. Cycle time tabulation - roller assembly

\begin{tabular}{|c|c|c|c|}
\hline & T13 & T23 & T50 \\
\hline Induction Hardening & 116 & 286 & 617 \\
\hline MPI & 106 & 245 & 402 \\
\hline Welding & 516 & 632 & 1126 \\
\hline Turning & 739 & 542 & 2434 \\
\hline Assembly & 1000 & 1100 & 1300 \\
\hline
\end{tabular}

The cycle from the work study can be used for finding out the observed and normal times respectively. Equations (2) and (3) represent the formulas used for calculating the normal and standard times.

$$
\begin{aligned}
& \text { Normal Time }=\text { Observed time } * \text { Rating } \\
& \text { Standard time }=\text { Normal Time }+ \text { Allowance }
\end{aligned}
$$

Based on the cycle time observed from time study, the normal and standard times are calculated which describe the actual cycle time. The standard times take into account delays due to various factors with respect to the worker and the working environment.

For the underlying problem, Pareto diagrams for the cycle times of the production of deck rollers were developed. Figure (5) represent the Pareto diagrams for the manufacture of the deck rollers giving information about the various processing times in their manufacturing. 
The chart depicts the cycle times for the different processes in the production of the deck roller along with the calculated Takt time. The diagram brings to attention the extra time needed in the drilling and boring process which is considered as waste and which has to be eliminated.

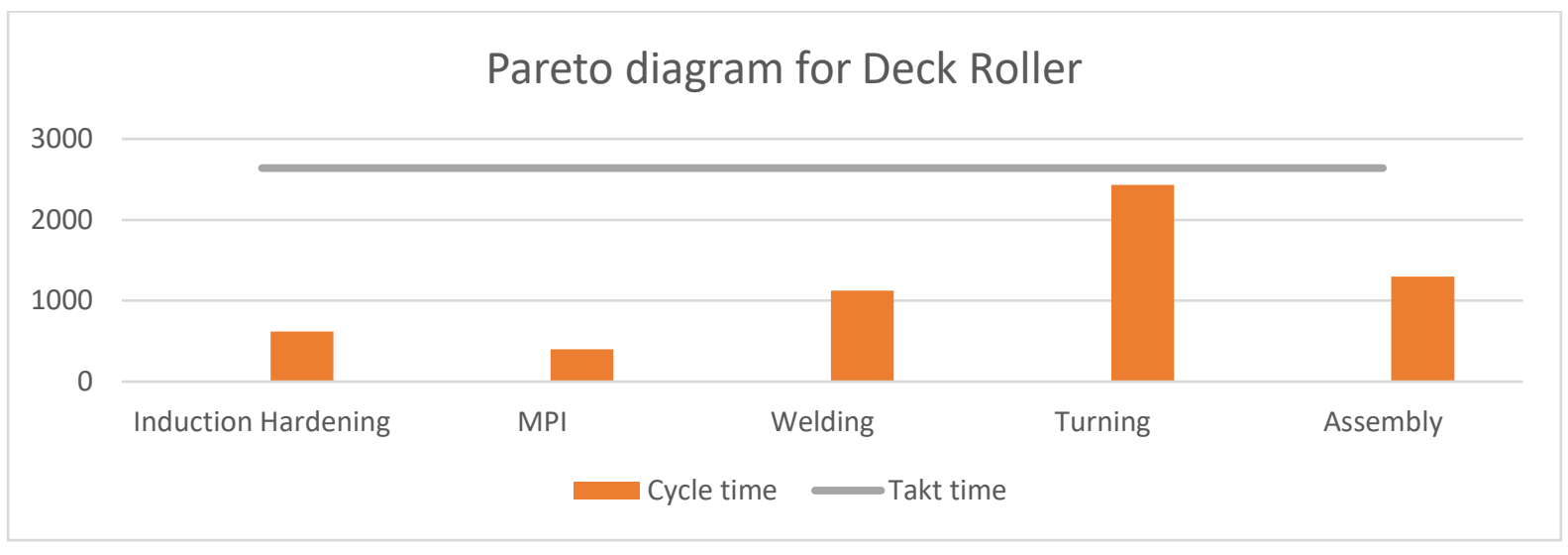

Figure 5. Pareto diagram for T23 Deck Roller.

\subsection{Analysis of current to future value stream map}

\subsubsection{Current value stream map}

The present value stream map has been generated using the information obtained from the proposed methodology. For the production of deck rollers the Takt times, cycle times (CTs) of different processes, the utilization of the machines, and convert times (Cos) were calculated. Figure (6) demonstrates the current value stream map for the production of the T23 Deck roller. In the figure the different processes required in the manufacture of the deck roller are shown in boxes along with the information about the number of operators needed for each process. Also, every process has a data box underneath which includes the CT of the processes and the CO time. Different lead times between the various processes are also shown in the form of a timeline, which helps in analyzing the total lead time for the product that comes out to be five days. The second component of the timeline is the value-added or processing time which is approximately 6058 seconds along with a lead time of 29 days. This is found by the summation of the processing times of all the processes. 


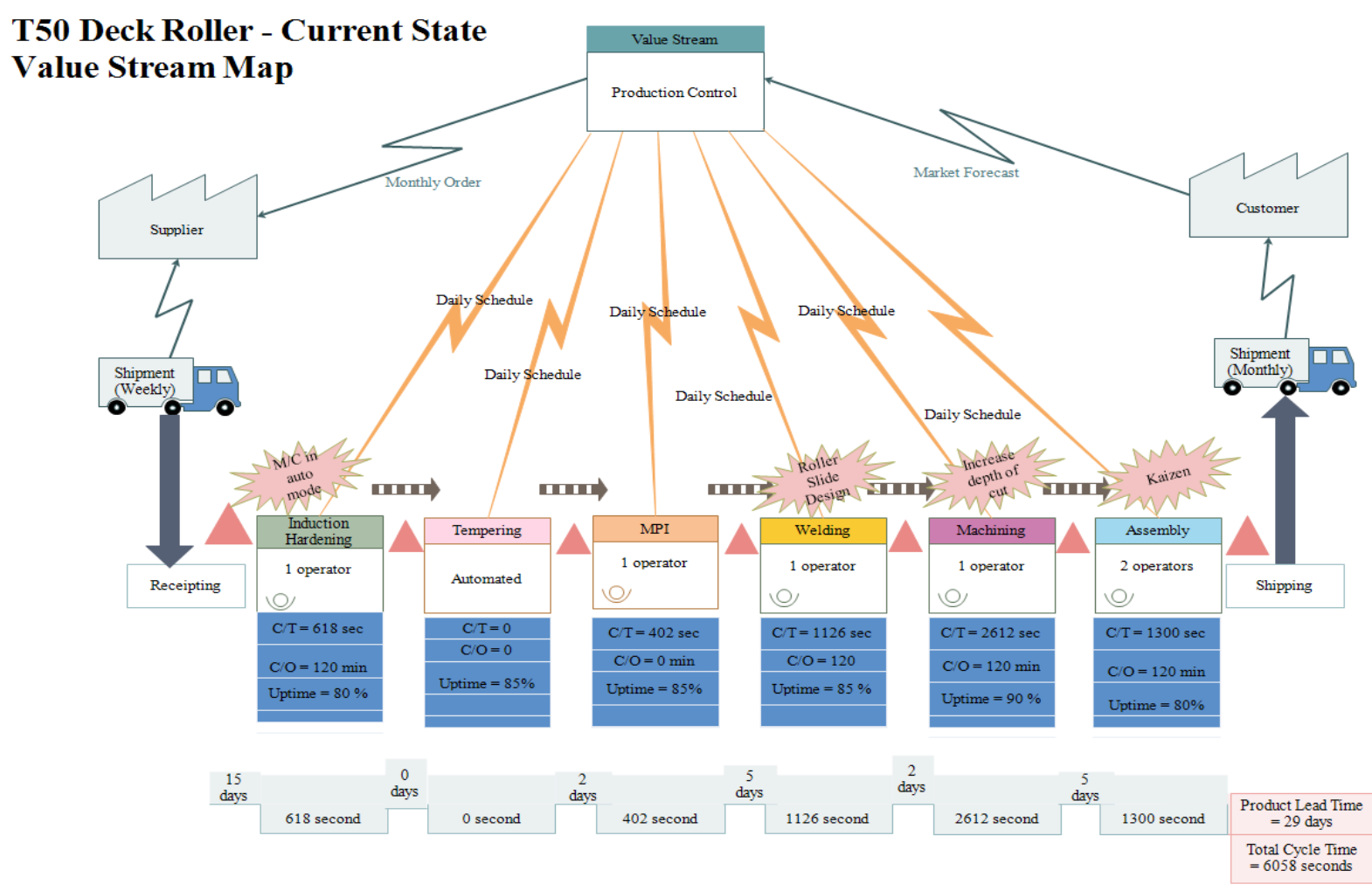

Figure 6. Current value stream map for T50 deck roller.

\subsection{Managerial Relevance}

\subsubsection{Low depth of cut in T50 deck roller CNC machining}

The machining time of T50 deck roller was around 44 minutes which was twice than that required for T23 deck roller. This was due to the low depth of cut used in the CNC program. Roughing and finishing cycle were used for T50 deck roller because the amount of material to be removed was much more than that of T23 deck roller. Since the total machining time went beyond the Takt time limit, the roughing cycle was eliminated from the process. Also, the dimensions of the T50 deck roller raw material was found to be much larger than the required dimensions after machining. So steps were taken to reduce the size of the raw material and the depth of cut was also increased. The steps lead to a decrease in cycle time from 44 mins to 25 mins. 


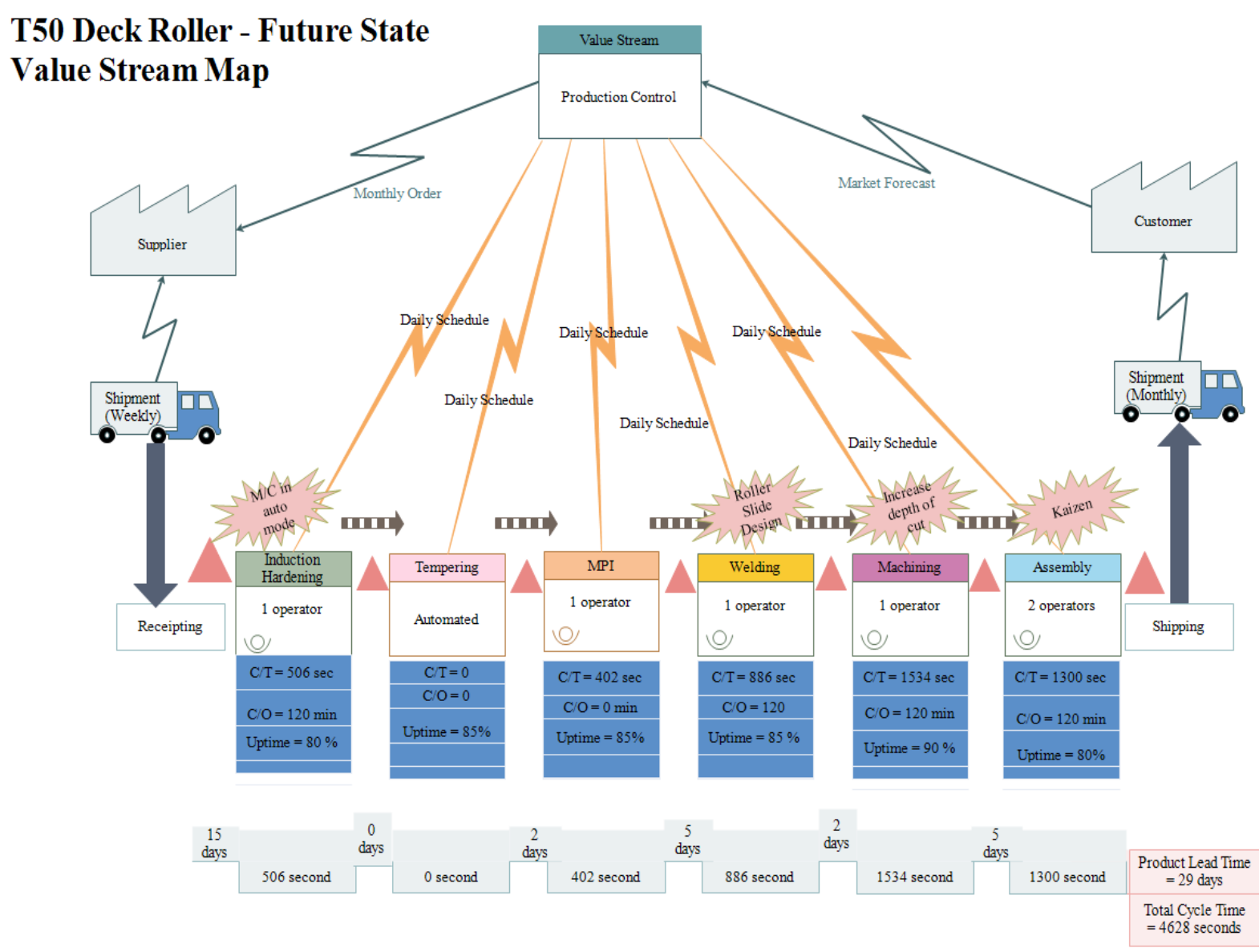

Figure 7. Future value stream map for T50 deck roller.

The improvements in the production rate of the deck roller by using low depth of cut in CNC machining can be observed through the future value stream map in Figure. (7). As shown in the figure the total cycle time has been reduced to 4628 seconds which in turn increased the production rate.

\subsubsection{Handling Time Reduction in Roller Welding}

In the welding of Deck Rollers, the roller rims must be lifted from the workspace manually and then mounted on the welding machine. Two roller rims must be welded together to form a Deck roller. After the welding process, the roller becomes so hot that it could not be unloaded immediately. So the worker was forced to wait for some time till the roller cools down to a certain extent. Besides being hot, the roller was so heavy that the worker experienced fatigue after some period. This caused higher cycle time in welding of all the roller variants. So a wheel mounted slide was designed in such a way that the roller slides on the slide to reach the floor instead of manually unloading it and placing it on the floor. As soon as the welded roller is 
unclamped, it drops on the slide and reaches the floor. So the waiting time of the worker is eliminated. This resulted in reduced cycle time as well as reduced workload for the operator.

Table 4. OEE calculation after slide

\begin{tabular}{|l|l|}
\hline Shift length & 9 hours \\
\hline Meal break & 1 \\
\hline Downtime & 1 hour \\
\hline Ideal run time & 7 parts/hour \\
\hline Total & 35 \\
\hline Rejected pieces & 1 \\
\hline Planned production time & 8 hours \\
\hline Operating time & 7 hours \\
\hline Good pieces & 34 \\
\hline
\end{tabular}

Table 5. OEE calculation after slide

\begin{tabular}{|l|l|}
\hline Shift length & 9 hours \\
\hline Meal break & 1 \\
\hline Downtime & 1 hour \\
\hline Ideal run time & 7 parts/hour \\
\hline Total & 41 \\
\hline Rejected pieces & 1 \\
\hline Planned production time & 8 hours \\
\hline Operating time & 7 hours \\
\hline Good pieces & 40 \\
\hline
\end{tabular}


Performance $=($ number of good pieces available $/$ operating time $) /$ Ideal run time

$$
\begin{aligned}
& \text { Quality = number of good pieces / Total number of pieces } \\
& \mathrm{OEE}=\text { Availability * Performance * Quality }
\end{aligned}
$$

Calculations for the OEE were done when the roller was produced before the use of slide and also after the use of the slide. Table 4 showed the data about the production when the slide was not used. By using the equations 4, 5 and 6 availability was obtained as 0.875 ; performance was found to be 0.714 while the quality was 0.971 . Finally, the OEE was obtained from the equation. 7 as 0.61 . Similar calculations were carried when the slide was used in the production to get the different parameters by using the data from the Table. 5. Availability came out to be 0.875 ; the performance was measured to be 0.816 , and the quality was improved to 0.9756 . The OEE for the new method came was calculated to be 0.7 . It can be seen that the reduction of cycle time because of the roller slide led to an increase in OEE from $61 \%$ to $70 \%$

\section{Arena Simulation and results discussion}

The T50 deck roller production line is modeled using arena simulation software. Figure (8) visually represents the total number of units entering the system for different processes in the T23 deck roller assembly and also shows the number of units that go out of the production sequence. Depending upon the cycle times and the mean waiting times in the queues for different processes, the utilization of the machines for the different machines is calculated via simulation and the result is depicted in the bar graph in figure (9). 


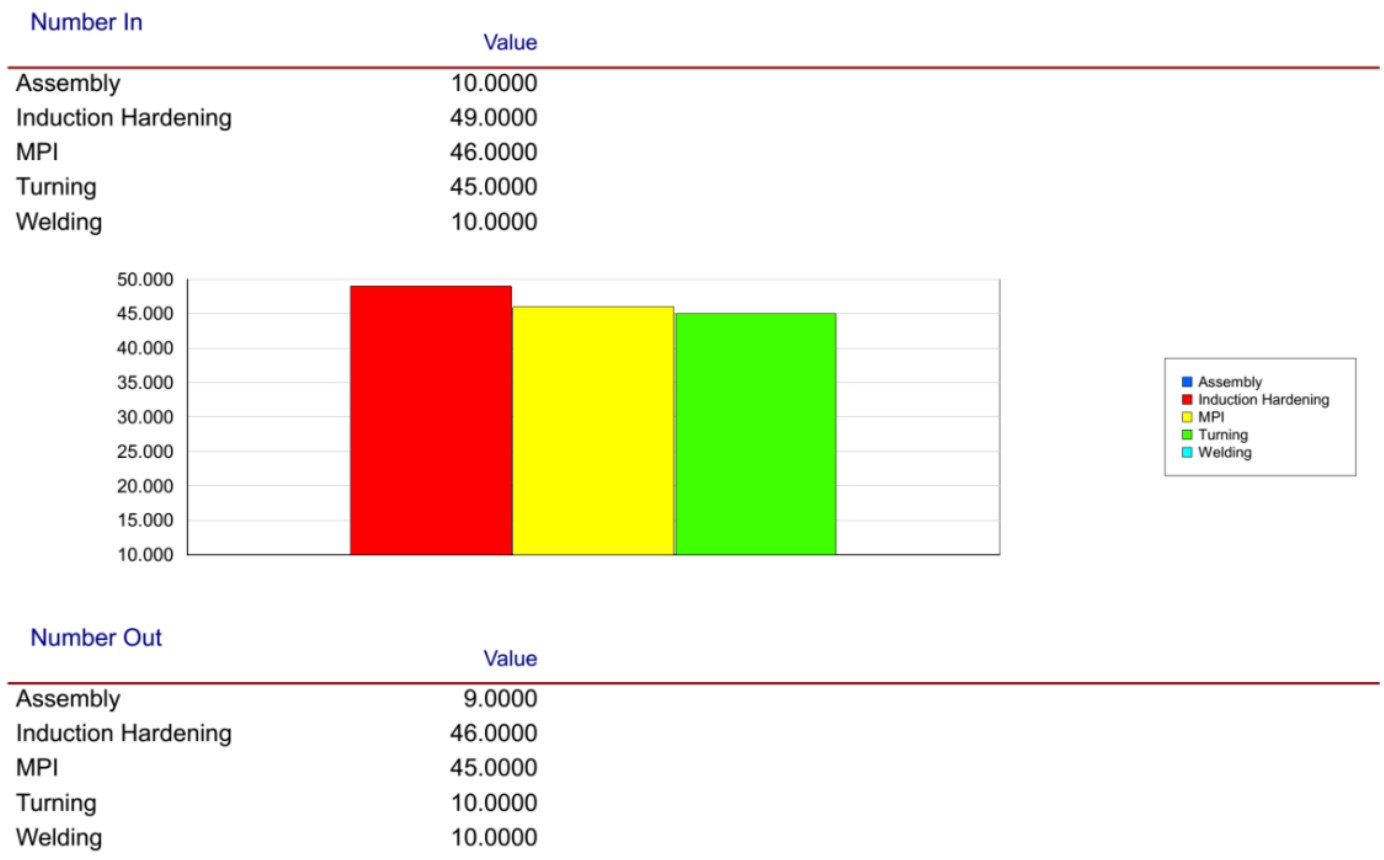

Figure 8. T50 deck roller current VSM - Number in and out.

\begin{tabular}{lr} 
Scheduled Utilization & Value \\
\hline Assembly Machine & 0.4206 \\
Induction Hardening Machine & 0.9993 \\
MPI machine & 0.6397 \\
Turning Machine & 0.9622 \\
Welding machine & 0.3910
\end{tabular}

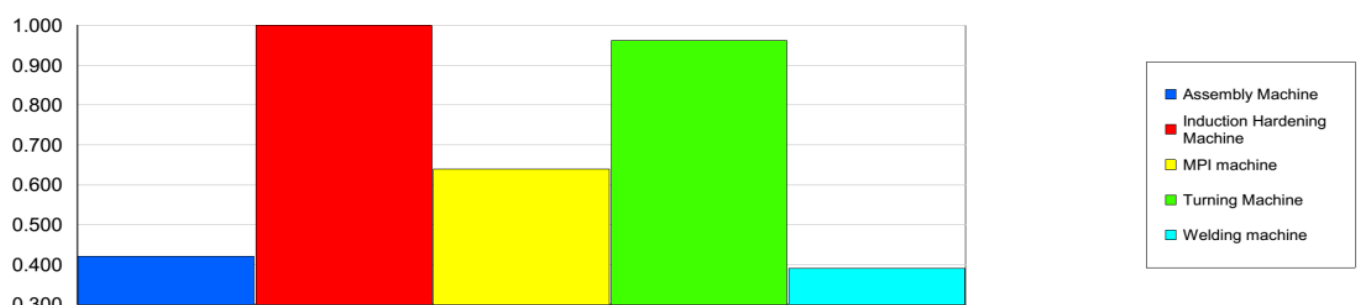

Figure 9. T50 deck roller current VSM - utilization. 


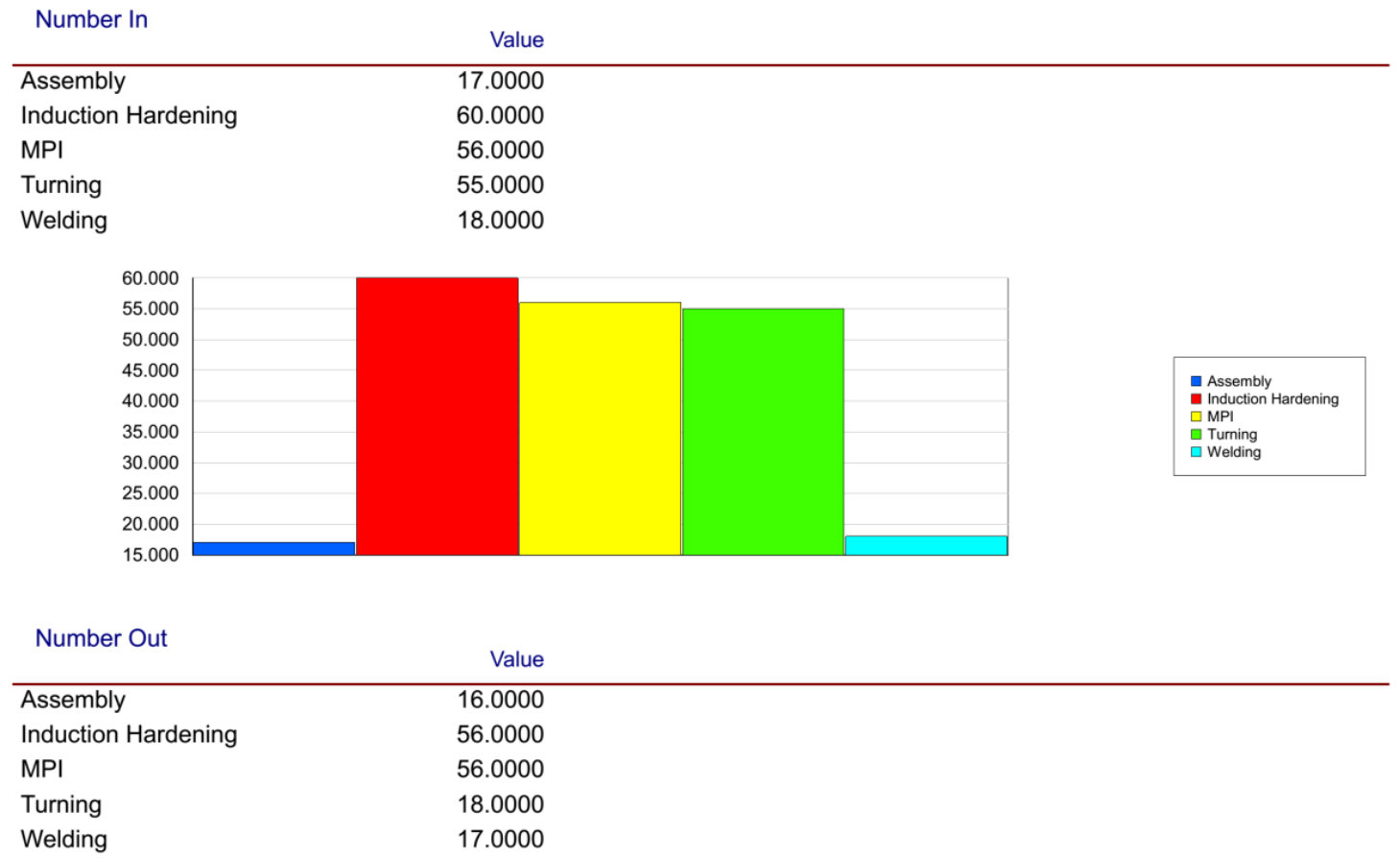

Figure 10. T50 Deck roller Future VSM - Number in and out.

\begin{tabular}{lr}
\multicolumn{1}{c}{ Scheduled Utilization } & Value \\
\hline Assembly Machine & 0.7503 \\
Induction Hardening Machine & 0.9993 \\
MPI machine & 0.7817 \\
Turning Machine & 0.9660 \\
Welding machine & 0.5296
\end{tabular}

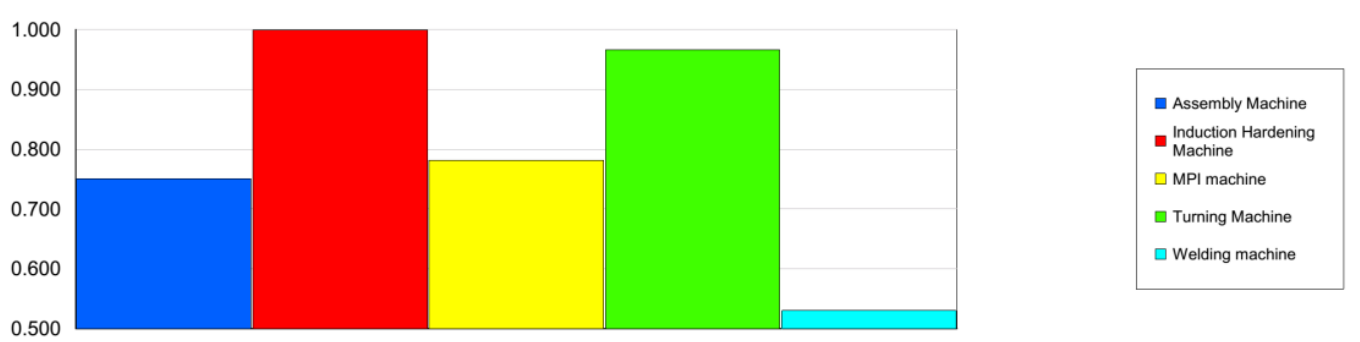

Figure 11. T50 Deck roller Future VSM - Utilization.

Figure (10) shows the number of units in and out of different processes in the assembly sequence after the implementation of the various waste reduction techniques. As the number of units in the system has increased as compared to the current map, the utilization of the machines has also been increased in the future map as shown in figure (11).

Table 6 represents the information regarding the enhancement in the future stream map for the production of T50 deck roller as compared to its current value stream map. This change 
is due to the application of low depth of cut in the CNC machining of the deck roller along with the different lean tools. The change in the machine utilization from 0.42 to 0.75 is reflected through the increase in daily production from 9 rollers to 16 rollers and decrease in the cycle time of the production from 6058 to 4628 seconds.

Table 6. Current state vs. future state for T50 deck roller production

\begin{tabular}{|c|c|c|}
\hline & CURRENT VSM & FUTURE VSM \\
\hline Daily production & 9 rollers & 16 rollers \\
\hline $\begin{array}{c}\text { Assembly machine } \\
\text { utilization }\end{array}$ & 0.42 & 0.75 \\
\hline $\begin{array}{c}\text { Induction hardening } \\
\text { number out }\end{array}$ & 45 & 56 \\
\hline Cycle time & $6058 \mathrm{sec}$ & $4628 \mathrm{sec}$ \\
\hline
\end{tabular}

\section{Conclusion}

This paper focuses on the cycle time reduction in the production of deck roller in an $\mathrm{ABC}$ manufacturing company. Different strategies and the use of lean tools and principles achieved the goals of waste reduction leading to higher efficiency in the production of the components. The current value stream map was developed to get a comprehensive idea about the existing production system by using the $3 \mathrm{G}$ and Kanban techniques to eliminate the wastes from the inventory. A time study was used to measure the cycle time of all the processes while work measurement was done to categorize the work elements into value added and non-value added activities. Future value stream map was developed to study the effects of the changes included in the production system on the production parameters like machine utilization, daily production and cycle times and then was compared with the current value stream map. The experimental results obtained after comparison of the current and future value stream mapping analysis proved that value stream mapping synergized with Lean principles for optimization of cycle time. Where, for the production of deck roller assembly with around $48 \%$ improvement in daily production activities, an average of $30 \%$ improvement in the utilization of available machines and the cycle time is improved by more than $1000 \mathrm{sec}$. 


\section{Acknowledgment}

This work has been supported by COMPETE: POCI-01-0145-FEDER-007043 and FCT Fundação para a Ciência e Tecnologia within the Project Scope: UID/CEC/00319/2013.

\section{References}

Arvind R., Dr.N. Gunasekaran, 2014. A Literature Review on Cycle Time Reduction in Material Handling System by Value Stream Mapping. International Journal for Research in Applied Science and Engineering Technology (IJRASET). Volume 2 Issue XII, ISSN: 2321-9653.

Gnanavel S.S., Venkatesh Balasubramanian, T.T. Narendran. Suzhal, 2015. An alternative layout to improve productivity and worker well-being in labor demanded lean environment. 6th International Conference on Applied Human Factors and Ergonomics and the Affiliated Conferences.

Rahul Pulkurte, Ravindran Masilamani, Sarvesh Sonpatki, Rajesh Dhake, 2014. Cycle time reduction in assembly line through layoutimprovement, ergonomics analysis and lean principles. International Journal of Applied Sciences and Engineering Research, Vol. 3, No. 2.

Sandip K. Kumbhar, Niranjan M.R, Sanjay T. Satpute, 2014. Assembly Line Production Improvement by optimization Of Cycle Time. Proceedings of 10th IRF International Conference, 978-93-84209-23-0, Pune, India.

Stefan Seifermann, Jörg Böllhoff, Joachim Metternich and Amin Bellaghnach, (2014). Evaluation of Work Measurement Concepts for a Cellular Manufacturing Reference Line to enable Low Cost Automation for Lean Machining. Proceedings of the 47th CIRP Conference on Manufacturing Systems.

Sundar R., A.N.Balaji, R.M.SatheeshKumar, 2014. A Review on Lean Manufacturing Implementation Techniques. 12th Global Congress on Manufacturing And Management, GCMM.

Yadong Fang, 2015. A method of meta-mechanism combination and replacement based on motion study. Journal of Production and manufacturing research, Vol. 3, issue 1, pp 310-323. 